\title{
Clinical implications of molecular studies for the diagnosis of thyroid cancer
}

\author{
Markus Eszlinger ${ }^{1}$, Kurt Werner Schmid ${ }^{2}$, Ralf Paschke ${ }^{1}$ \\ ${ }^{1} 3^{\text {rd }}$ Medical Department, University of Leipzig, Leipzig, ${ }^{2}$ Institute of Pathology and Neuropathology, University Hospital \\ of Essen, University of Duisburg-Essen, Hufelandstraße 55, 45122 Essen, Germany
}

The evaluation of patients with nodular thyroid disease is focused on two main aspects, namely the exclusion of thyroid malignancy and the exclusion of hyperthyroidism in regions with borderline iodine supply. However, the identification and preoperative typing of both the substantially less frequently occurring thyroid carcinomas (2-5\% of all nodules) and the frequently occurring benign thyroid nodules ( $30 \%$ in the general population) is challenging. Currently, the typing of thyroid carcinomas is based on the morphologic criteria outlined by the WHO classification (Table 1). ${ }^{1}$ Due to difficulties involved in clearly differentiating between carcinoma and benign nodular lesions, the categorization of certain thyroid tumours as tumours with low malignant potential has been proposed. ${ }^{2}$ However, the molecular pathologic characterization of thyroid nodules seems to offer the opportunity of a more comprehensive definition of thyroid tumour subtypes.

Key words: Thyroid cancer, Follicular thyroid adenoma, Follicular thyroid carcinoma, Molecular studies

Address for correspondence:

Ralf Paschke, M.D., III. Medical Department, University of Leipzig, Ph.-Rosenthal-Str. 27, D-04103 Leipzig, Germany, Phone: +49 341 9713201, Fax: +49341 9713209, e-mail: pasr@medizin.uni-leipzig.de

Received 03-04-09, Revised 05-09-09, Accepted 10-10-09
Thyroid ultrasound is used to evaluate the size and structure of the thyroid and its nodules. It is also helpful to guide Fine Needle Biopsy (FNB) and to monitor changes in the size of thyroid nodules. However, the value of sonography to discriminate malignant from benign thyroid nodules is limited. Although ultrasound-based features like hypoechoic structure, presence of calcifications, irregular margins, absence of a halo, solid composition, and intranodular vascularity have been associated with an increased risk of thyroid cancer, particularly in the US American literature, the results differ considerably between studies; no single feature or combination of features offers both the sensitivity and high positive predictive value required to unanimously accept this method for the diagnosis of thyroid cancer. ${ }^{3,4}$

FNB, currently the most sensitive and specific tool for the preoperative identification of thyroid malignancy, also has substantial limitations. While approximately $75 \%$ of FNBs reveal benign lesions, and $5 \%$ malignancy, up to $20 \%$ of FNBs belong to the group of follicular proliferations [Follicular Adenoma (FA), Follicular Thyroid Carcinoma (FTC), or the Follicular Variant of Papillary Thyroid Carcinomas (FVPTC)], which can be distinguished only histologically, thus necessitating thyroid surgery. ${ }^{5}$ As a consequence, the percentage of malignancies among the resected thyroids with follicular proliferations is rather low (the highest reported thyroid carcinoma frequency with vigorous FNB selection of all operated nodules was $34 \%^{6}$ ) and hence the majority (up to $80 \%$ according 
to Löwhagen et al) of the respective patients end up being operated on for a benign nodule. ${ }^{7}$

Whereas both the histologic diagnosis of nonminimally invasive FTC and the majority of FA show an acceptable inter- and intraobserver variability, the differential diagnosis of minimally invasive FTC and hypercellular (atypical) FA may be extremely difficult. Even the most objective histologic criteria for the diagnosis of minimally invasive FTC, e.g. vascular and/or capsular invasion, show high inter- and intraobserver variations. ${ }^{8-10}$ Lang et $\mathrm{a}^{11}$ demonstrated as much as 20 years ago that the examination of an adequate number of tissue blocks is required to reliably differentiate FTC from FA. These results clearly indicate that the diagnosis of FTC depends on both the experience and training status of the pathologist as well the pathologist's efforts to sufficiently investigate thyroid nodules. Hence, the limitations in the diagnosis of minimally invasive FTCs questions the validity of published results concerning the incidence, prognosis, treatment, and outcome of FTCs,${ }^{10}$ since the rate of distant metastasis and death due to follicular carcinomas is highly influenced by the degree of (angio-)invasion. ${ }^{12,13}$ Thus, for a precise diagnosis of encapsulated follicular lesions, the use of molecular markers for improving the discrimination between minimally invasive follicular carcinoma and (hypercellular/atypical) follicular adenoma are most desirable. ${ }^{8}$

Although a growing number of immunohistochemical markers for the discrimination between benign and malignant thyroid tumours have been proposed over the last few years, ${ }^{14}$ no one marker or marker combination is able to identify tumour aggressiveness.

One obvious reason for the difficulty in precisely discriminating FTC from FA is the limited knowledge about the molecular aetiology of Cold Thyroid Nodules (CTNs) or scintigraphically isocaptant nodules which are histologically defined as follicular adenomas or adenomatoid nodules, which comprise approximately $85 \%$ of all thyroid tumours. In contrast to CTNs and the scintigraphically isocaptant nodules, the molecular aetiology of autonomously functioning thyroid nodules is characterized by constitutively activating mutations of the TSH receptor in about $60 \%$ of the nodules..$^{15-17}$
In FTCs, both activating $R A S$ mutations (in about $40-53 \%$ of $\mathrm{FTCs}^{18}$ ) and a fusion oncogene between $P A X 8$ and PPAR (in about $25-63 \%$ of $\mathrm{FTCs}^{19}$ ) have been detected; both molecular alterations have been demonstrated, although less frequently, in FA, which hampers their use as markers of malignancy. The vast majority of PTC are characterized by mutations or re-arrangements along the MAPK signalling cascade [depending on the PTC subtype (Table 1), RET/PTC re-arrangements are found in $13-43 \%$, and $B R A F$ mutations in $29-69 \%$ of $\left.\mathrm{PTC}^{19}\right]$. In the light of these findings the diagnostic potential of $R E T / P T C$ re-arrangements and $B R A F$ mutations has been investigated in FNA samples in several studies. ${ }^{20-27}$ The $B R A F$ mutation was detected in $38-83 \%$ of the investigated FNA samples that were PTC on histopathology, ${ }^{20,22,26}$ indicating that the screening for $B R A F$ mutations in

Table 1. Tumours of the thyroid according to DeLellis et al. WHO Classification of Tumours $2004^{1}$

- Papillary carcinoma

Histopathological variants:

- Follicular variant

- Macrofollicular variant

- Oncocytic variant

- Clear cell variant

- Diffuse sclerosing variant

- Solid variant

- Cribriform carcinoma

- Papillary carcinoma with focal insular component

- Papillary carcinoma with squamous cell or mucoepidermoid carcinoma

- Papillary carcinoma with spindle and giant cell carcinoma

- Combined papillary and medullary carcinoma

- Papillary microcarcinomas

- Follicular carcinoma

- Minimally invasive

- Widely invasive

Cytological variants:

- Oncocytic variant

- Clear cell variant

- Poorly differentiated carcinoma

- Undifferentiated (anaplastic) carcinoma

- Medullary thyroid carcinoma

- Follicular adenoma 
FNB samples may be a useful adjunct technique for the evaluation of thyroid nodules with indeterminate and suspicious cytological findings, taking into consideration that $B R A F$ mutations demonstrate a high geographical variability. Thus, compared to most European countries with relatively high incidence of follicular lesions, the diagnostic impact of demonstrating $B R A F$ mutations is considerably higher in countries with a high iodine uptake, e.g. Korea. ${ }^{20,28,29}$ With respect to the histological subtype, $B R A F$ mutations seem to be more common in the conventional variant of PTC than in the FV-PTC. ${ }^{22,26}$

Although the uncovering of the molecular aetiology of about $60 \%$ of follicular and papillary thyroid carcinomas did provide new perspectives for the classification and diagnosis of thyroid tumours, it became rapidly apparent that the incidence of detected somatic mutations in FTCs and PTCs varies in different studies ${ }^{19}$ and that various methods of mutation screening (e.g. direct sequencing, denaturing gradient gel electrophoresis, LightCycler PCR, PCR-RFLP) are characterized by different sensitivities. ${ }^{20,25,30,31} \mathrm{In}$ fact, the use of very sensitive methods led to the detection of $R E T / P T C$ rearrangements, thought to be specific for papillary thyroid carcinoma, in Hashimoto's disease $^{32}$ and $P A X 8 / P P A R \gamma$ rearrangements, thought to be specific for thyroid follicular carcinomas, in some thyroid adenomas. ${ }^{33-35}$ However, genetic events are certainly already taking place before malignancy is detectable by histology. Therefore, without knowing the precise molecular basis of thyroid carcinomas it is difficult to diagnose thyroid carcinoma by molecular markers.

Apart from standardization of tissue sample processing, one way out of the discrepancy between histologic and molecular tumour classification, and the methodological limitations of mutation screening, might be the diagnostic application of gene expression signatures. In the thyroid field this can be accomplished with the help of microarrays (for review see $\left.{ }^{36}\right)$. However, despite the fact that microarray studies revealed very distinct changes in the expression of certain genes, none of the genes, identified by array studies as differentially regulated, was proven to be an ideal single marker of PTC. ${ }^{37-46}$ For example, DPP4 (dipeptidyl-peptidase 4) shown to be the most up-regulated gene in PTC, ${ }^{47,48}$ did not clearly differentiate between PTC and benign tissue. ${ }^{49}$ Also, neither oncofibronectin, galectin 3, nor other proposed markers worked properly in a single gene context. $^{50-55}$ Therefore, a more promising approach to discriminate between benign and malignant tumours seems to be the generation and application of multigene classifiers. While a discriminating gene set comprising hundreds of genes is not applicable for diagnostic purposes, a powerful set (10 to 20) of discriminating genes generated by sophisticated bioinformatics approaches appears feasible for use in Real Time (RT)-PCR approaches. Interestingly, the 20 gene classifier discriminating PTCs from benign tissues, proposed by Jarzab et al, ${ }^{48}$ does not contain many known genes found in other approaches like Fibronectin 1 (FN1) or TIMP, whereas some other genes previously known for their up-regulation in PTC (e.g. DPP4, SERPINA1, LGALS3, MET) and some new genes previously not described in PTC (e.g. $E V A 1, L P R 4$ and $R X R G$ ) were included. While only some genes show a stable and very distinct difference in expression between PTCs and benign tissues, other genes included give slightly different results. These genes are overexpressed only in a subset of PTC and, in the case of lack of overexpression, the information is completed by the expression of other genes. Interestingly, this gene classifier did not only reliably classify different data sets of papillary carcinomas but also data sets of hot and cold thyroid nodules. ${ }^{48,56} \mathrm{In}$ other studies, malignant and benign samples could be differentiated by sets of only six genes. ${ }^{55,57-59} \mathrm{~A}$ further possibility to improve the diagnosis in FNB with cytological findings suspicious for thyroid cancer might be the combination of measuring differentially expressed genes and detecting cancer specific mutations (e.g. $B R A F, R E T / P T C$ ). A very promising study, based on the combined analysis of galectin-3 and the $B R A F^{V 600 E}$ mutation, has recently been published. ${ }^{60}$ Other studies using a three or four gene profiling of thyroid nodules have accurately distinguished between FTC and FA. ${ }^{61,62}$ Although most of these studies are very promising, almost all of them are based on the investigation of thyroid tissue samples. Therefore, the proposed markers need to be studied in FNB samples.

In conclusion, the currently established determinants of tumour diagnosis, classification, and prognosis 
based on tumour histology, immunohistochemistry, and tumour staging will be complemented in the future by molecular approaches such as the detection of genetic alterations and the identification of differentially expressed genes. The application of both histologic and molecular markers will refine the definition of thyroid tumours and will help to better characterize tumours with histologically uncertain biological behaviour. Based on the further understanding of the molecular evolution of thyroid tumours, these approaches must go beyond simple correlations of histologic classifications and molecular markers. They will most likely lead to a better prediction of the risk for invasion, metastasis, and progression. Moreover, molecular markers will provide a more solid basis for an optimized and individualized treatment of thyroid cancer and ultimately will improve survival of patients.

\section{REFERENCES}

1. DeLellis RA, Williams ED, LiVolsi V, et al 2004 Tumours of the Thyroid and Parathyroid. In: DeLellis RA, Lloyd RV, Heitz PU, Eng C (eds) WHO Classification of Tumours: Pathology \& Genetics of Tumours of Endocrine Organs, Lyon: IARC Press; pp, 51-103.

2. Williams ED 2000 Guest Editorial: Two Proposals Regarding the Terminology of Thyroid Tumors. Int $\mathbf{J}$ Surg Pathol 8: 181-183.

3. Frates MC, Benson CB, Charboneau JW, et al, 2005 Management of thyroid nodules detected at US: Society of Radiologists in Ultrasound consensus conference statement. Radiology 237: 794-800.

4. Varverakis E, Neonakis E, 2002 Contribution of highresolution ultrasonography in the differential diagnosis of benign from malignant thyroid nodules. Hormones (Athens) 1: 51-56.

5. Gharib H, 1997 Changing concepts in the diagnosis and management of thyroid nodules. Endocrinol Metab Clin North Am 26: 777-800.

6. Carpi A, Ferrari E, Toni MG, et al, 1996 Needle aspiration techniques in preoperative selection of patients with thyroid nodules: a long-term study. J Clin Oncol 14: $1704-1712$.

7. Lowhagen T, Granberg PO, Lundell G, et al, 1979 Aspiration biopsy cytology $(\mathrm{ABC})$ in nodules of the thyroid gland suspected to be malignant. Surg Clin North Am 59: 3-18.

8. Schmid KW, Farid NR, 2006 How to define follicular thyroid carcinoma? Virchows Arch 448: 385-393.

9. Chan JKC, Hirokawa, M, Evans H, et al 2004 Tumours of the Thyroid and Parathyroid: Follicular adenoma. In:
DeLellis RA, Lloyd RV, Heitz PU, Eng C (eds) WHO Classification of Tumours: Pathology \& Genetics of Tumours of Endocrine Organs, Lyon: IARCPress; pp, 98-103.

10. Franc B, de la Salmoniere P, Lange F, et al, 2003 Interobserver and intraobserver reproducibility in the histopathology of follicular thyroid carcinoma. Hum Pathol 34: 1092-1100.

11. Lang W, Georgii A, Stauch G, Kienzle E, 1980 The differentiation of atypical adenomas and encapsulated follicular carcinomas in the thyroid gland. Virchows Arch. A Pathol Anat Histol 385: 125-141.

12. Lang W, Choritz H, Hundeshagen H, 1986 Risk factors in follicular thyroid carcinomas. A retrospective follow-up study covering a 14-year period with emphasis on morphological findings. Am J Surg Pathol 10: 246-255.

13. Schmid KW, Totsch M, Ofner D, et al, 1997 Minimally invasive follicular thyroid carcinoma: a clinico-pathological study. Curr Top Pathol 91: 37-43.

14. Faggiano A, Caillou B, Lacroix L, et al, 2007 Functional characterization of human thyroid tissue with immunohistochemistry. Thyroid 17: 203-211.

15. Paschke R, Ludgate M, 1997 The thyrotropin receptor in thyroid diseases. N Engl J Med 337: 1675-1681.

16. Trulzsch B, Krohn K, Wonerow P, et al,2001 Detection of thyroid-stimulating hormone receptor and Gsalpha mutations: in 75 toxic thyroid nodules by denaturing gradient gel electrophoresis. J Mol Med 78: 684-691.

17. Sykiotis PG, Sgourou A, Papachatzopoulou A, et al, 2002 A somatic mutation in the thyrotropin receptor gene in a patient with an autonomous nodule within a mulitnodular goiter. Hormones (Athens) 1: 42-46.

18. Fagin JA, 2002 Mini review: branded from the start-distinct oncogenic initiating events may determine tumor fate in the thyroid. Mol Endocrinol 16: 903-911.

19. Kondo T, Ezzat S, Asa SL, 2006 Pathogenetic mechanisms in thyroid follicular-cell neoplasia. Nat Rev Cancer 6: 292-306.

20. Chung KW, Yang SK, Lee GK, et al, 2006 Detection of BRAFV600E mutation on fine needle aspiration specimens of thyroid nodule refines cyto-pathology diagnosis, especially in BRAF600E mutation-prevalent area. Clin Endocrinol (Oxf) 65: 660-666.

21. Tetzlaff MT, LiVolsi V, Baloch ZW, 2006 Assessing the utility of a mutational assay for B-RAF as an adjunct to conventional fine needle aspiration of the thyroid gland. Adv Anat Pathol 13: 228-237.

22. Cohen Y, Rosenbaum E, Clark DP, et al, 2004 Mutational analysis of BRAF in fine needle aspiration biopsies of the thyroid: a potential application for the preoperative assessment of thyroid nodules. Clin Cancer Res 10: 27612765.

23. Jin L, Sebo TJ, Nakamura N, et al, 2006 BRAF mutation analysis in fine needle aspiration (FNA) cytology of the thyroid. Diagn Mol Pathol 15: 136-143.

24. Pizzolanti G, Russo L, Richiusa P, et al, 2007 Fine-needle 
aspiration molecular analysis for the diagnosis of papillary thyroid carcinoma through BRAF(V600E) mutation and RET/PTC rearrangement. Thyroid 17: 1109-1115.

25. Rowe LM, Bentz BM, Bentz JM, 2006 Utility of BRAF V600E mutation detection in cytologically indeterminate thyroid nodules. Cytojournal 3: 10.

26. Salvatore G, Giannini R, Faviana P, et al, 2004 Analysis of BRAF point mutation and RET/PTC rearrangement refines the fine-needle aspiration diagnosis of papillary thyroid carcinoma. J Clin Endocrinol Metab 89: 51755180.

27. Sapio MR, Posca D, Raggioli A, et al, 2007 Detection of RET/PTC, TRK and BRAF mutations in preoperative diagnosis of thyroid nodules with indeterminate cytological findings. Clin Endocrinol (Oxf) 66: 678-683.

28. Kim KH, Kang DW, Kim SH, et al, 2004 Mutations of the BRAF gene in papillary thyroid carcinoma in a Korean population. Yonsei Med J 45: 818-821.

29. Kim TY, Kim WB, Song JY, et al, 2005 The BRAFV600E mutation is not associated with poor prognostic factors in Korean patients with conventional papillary thyroid microcarcinoma. Clinical Endocrinology 63: 588-593.

30. Trulzsch B, Krohn K, Wonerow P, Paschke R, 1999 DGGE is more sensitive for the detection of somatic point mutations than direct sequencing. Biotechniques 27: 266-268.

31. Zhu Z, Ciampi R, Nikiforova MN, et al, 2006 Prevalence of RET/PTC rearrangements in thyroid papillary carcinomas: effects of the detection methods and genetic heterogeneity. J Clin Endocrinol Metab 91: 3603-3610.

32. Rhoden KJ, Unger K, Salvatore G, et al, 2006 RET/papillary thyroid cancer rearrangement in nonneoplastic thyrocytes: follicular cells of Hashimoto's thyroiditis share low-level recombination events with a subset of papillary carcinoma. J Clin Endocrinol Metab 91: 2414-2423.

33. Cheung L, Messina M, Gill A, et al, 2003 Detection of the PAX8-PPAR gamma fusion oncogene in both follicular thyroid carcinomas and adenomas. J Clin Endocrinol Metab 88: 354-357.

34. Marques AR, Espadinha C, Catarino AL, et al, 2002 Expression of PAX8-PPAR gamma 1 rearrangements in both follicular thyroid carcinomas and adenomas. $\mathrm{J}$ Clin Endocrinol Metab 87: 3947-3952.

35. Nikiforova MN, Biddinger PW, Caudill CM, et al, 2002 PAX8-PPARgamma rearrangement in thyroid tumors: RT-PCR and immunohistochemical analyses. Am J Surg Pathol 26: 1016-1023.

36. Eszlinger M, Krohn K, Kukulska A, et al, 2007 Perspectives and Limitations of Microarray-Based Gene Expression Profiling of Thyroid Tumors. Endocr Rev 28: 322-338.

37. Aogi K, Kitahara K, Buley I, et al, 1998 Telomerase activity in lesions of the thyroid: application to diagnosis of clinical samples including fine-needle aspirates. Clin Cancer Res 4: 1965-1970.

38. Bernet VJ, Anderson J, Vaishnav Y, et al, 2002 De- termination of galectin-3 messenger ribonucleic acid overexpression in papillary thyroid cancer by quantitative reverse transcription-polymerase chain reaction. J Clin Endocrinol Metab 87: 4792-4796.

39. Casey MB, Lohse CM, Lloyd RV, 2003 Distinction between papillary thyroid hyperplasia and papillary thyroid carcinoma by immunohistochemical staining for cytokeratin 19, galectin-3, and HBME-1. Endocr Pathol 14: 55-60.

40. Haugen BR, Nawaz S, Markham N, et al, 1997 Telomerase activity in benign and malignant thyroid tumors. Thyroid 7: 337-342.

41. Inohara H, Honjo Y, Yoshii T, et al, 1999 Expression of galectin-3 in fine-needle aspirates as a diagnostic marker differentiating benign from malignant thyroid neoplasms. Cancer 85: 2475-2484.

42. Ippolito A, Vella V, La Rosa GL, et al, 2001 Immunostaining for Met/HGF receptor may be useful to identify malignancies in thyroid lesions classified suspicious at fine-needle aspiration biopsy. Thyroid 11: 783-787.

43. Mase T, Funahashi H, Koshikawa T, et al, 2003 HBME-1 immunostaining in thyroid tumors especially in follicular neoplasm. Endocr J 50: 173-177.

44. Raphael SJ, 2002 The meanings of markers: ancillary techniques in diagnosis of thyroid neoplasia. Endocr Pathol 13: 301-311.

45. Sack MJ, Astengo-Osuna C, Lin BT, et al, 1997 HBME1 immunostaining in thyroid fine-needle aspirations: a useful marker in the diagnosis of carcinoma. Mod Pathol 10: 668-674.

46. Saggiorato E, Cappia S, De Giuli P, et al, 2001 Galectin-3 as a presurgical immunocytodiagnostic marker of minimally invasive follicular thyroid carcinoma. J Clin Endocrinol Metab 86: 5152-5158.

47. Huang Y, Prasad M, Lemon WJ, et al, 2001 Gene expression in papillary thyroid carcinoma reveals highly consistent profiles. Proc Natl Acad Sci U.S.A. 98: 1504415049.

48. Jarzab B, Wiench M, Fujarewicz K, et al, 2005 Gene expression profile of papillary thyroid cancer: sources of variability and diagnostic implications. Cancer Res 65: 1587-1597.

49. Kholova I, Ryska A, Ludvikova M, et al, 2003 Dipeptidyl peptidase IV expression in thyroid cytology: retrospective histologically confirmed study. Cytopathology 14: 27-31.

50. Giannini R, Faviana P, Cavinato T, et al, 2003 Galectin-3 and oncofetal-fibronectin expression in thyroid neoplasia as assessed by reverse transcription-polymerase chain reaction and immunochemistry in cytologic and pathologic specimens. Thyroid 13: 765-770.

51. Papotti M, Rodriguez J, De Pompa R, et al, 2005 Galectin-3 and HBME-1 expression in well-differentiated thyroid tumors with follicular architecture of uncertain malignant potential. Mod Pathol 18: 541-546.

52. Prasad ML, Huang Y, Pellegata NS, et al, 2004 Hashi- 
moto's thyroiditis with papillary thyroid carcinoma (PTC)-like nuclear alterations express molecular markers of PTC. Histopathology 45: 39-46.

53. Saggiorato E, De Pompa R, Volante M, et al, 2005 Characterization of thyroid 'follicular neoplasms' in fine-needle aspiration cytological specimens using a panel of immunohistochemical markers: a proposal for clinical application. Endocr Relat Cancer 12: 305-317.

54. Takano T, Miyauchi A, Matsuzuka F, et al, 2000 Expression of oncofetal fibronectin messenger ribonucleic acid in fibroblasts in the thyroid: a possible cause of false positive results in molecular-based diagnosis of thyroid carcinomas. J Clin Endocrinol Metab 85: 765-768.

55. Krause K, Eszlinger M, Gimm O, et al, 2008 TFF3 based candidate gene discrimination of benign and malignant thyroid tumours in a region with borderline iodine deficiency. J Clin Endocrinol Metab 93: 1390-1393.

56. Eszlinger M, Wiench M, Jarzab B, et al, 2006 Meta- and reanalysis of gene expression profiles of hot and cold thyroid nodules and papillary thyroid carcinoma for gene groups. J Clin Endocrinol Metab 91: 1934-1942.

57. Fujarewicz K, Jarzab M, Eszlinger M, et al, 2007 A multi-gene approach to differentiate papillary thyroid carcinoma from benign lesions: gene selection using support vector machines with bootstrapping. Endocr Relat Cancer 14: 809-826.

58. Kebebew E, Peng M, Reiff E, McMillan A, 2006 Diagnostic and extent of disease multigene assay for malignant thyroid neoplasms. Cancer 106: 2592-2597.

59. Mazzanti C, Zeiger MA, Costouros NG, et al, 2004 Using gene expression profiling to differentiate benign versus malignant thyroid tumors. Cancer Res 64: 2898-2903.

60. Sapio MR, Guerra A, Posca D, et al, 2007 Combined analysis of galectin-3 and BRAFV600E improves the accuracy of fine-needle aspiration biopsy with cytological findings suspicious for papillary thyroid carcinoma. Endocr Relat Cancer 14: 1089-1097.

61. Cerutti JM, Delcelo R, Amadei MJ, et al, 2004 A preoperative diagnostic test that distinguishes benign from malignant thyroid carcinoma based on gene expression. J Clin Invest 113: 1234-1242.

62. Weber F, Shen L, Aldred MA, et al, 2005 Genetic classification of benign and malignant thyroid follicular neoplasia based on a 3-gene combination. J Clin Endocrinol Metab 90: 2512-2521. 